\title{
Generation of an Annual Typical Meteorological Solar Radiation for Armidale NSWAustralia
}

\author{
Yasser Maklad ${ }^{1}$ \\ ${ }^{1}$ (University of New England, Armidale NSW 2351 NSW Australia- School of Environmental \& Rural Science - \\ email: ymaklad@myune.edu.au)
}

\begin{abstract}
The most common data for describing the local solar climate is through what is called Typical Meteorological Year data (TMY). Typical solar radiation data is very important for the calculations of many solar applications. In this study, typical solar radiation years for Armidale town in New South Wales in Australia are generated from the daily global solar radiation data measured for 23 years, utilising the Finkelstein-Schafer statistical method. The study outcome is expected to show how solar irradiance is potential in Armidale NSW and would be a real help for solar energy generation systems' designers in this region for all building applications varying between residential, educational, administrative and commercial for sizing and maximising efficiency of such systems by using the tabular TYR outcome for the each day of the year.
\end{abstract}

Keywords:- Armidale NSW, solar radiation, test meteorological year, test reference yea

\section{INTRODUCTION}

The most common data for describing the local solar climate is through what is called Typical Meteorological Year data (TMY). To determine TMY data, various meteorological measurements are made at hourly intervals over a number of years to build up a picture of the local climate. A simple average of the yearly data underestimates the amount of variability, so the month that is most representative of the location is selected. For each month, the average radiation over the whole measurement period is determined, together with the average radiation in each month during the measurement period. The data for the month that has the average radiation most closely equal to the monthly average over the whole measurement period is then chosen as the TMY data for that month. This process is then repeated for each month in the year. The months are added together to give a full year of hourly samples. There is no strict standard for TMY data so the user must adjust the data to suit the application. Considerable care must be taken with sample periods. Solar radiation data is a crucial parameter for the prediction of long-term performance of solar energy generation systems. As well, it is a key input in modelling and designing of solar energy applications. Thus, a need for a reliable source of solar radiation data has to be readily available for particular settlement locations.

The need for a one-year representative daily meteorological data led to the development of methodologies known as the Typical Meteorological Year (TMY), alternatively called Test Reference Year (TRY) [1]. TMY or TRY is a representative data that consists of the month selected from the individual years and concatenated to form a complete year. However, A TMY is not necessarily a good indicator of conditions over the next year or even the next five years. Rather, TMY represents conditions judged to be typical over a long period of time [2]. Typical weather year data sets can be generated for several climatic variables such as temperature, humidity, wind speed, etc. or only for solar radiation. Various trials have been made to generate such weather databases for different areas around the world [1, 3, 4, 5, 6, 7, 8, 9\&10].

The main aim of this study is to generate representative TYM solar radiation data for Armidale NSW, Australia

\section{DATA AND LOCATION}

The daily global solar radiations recorded during the period 1980-2012 are utilized to generate the typical solar radiation data. In Australia, meteorological observations are recorded by the Australian Bureau of Meteorology (BOM) weather stations are widely spreader in lots of cities and towns around Australia. In this study, the global solar radiation data recorded by Armidale Airport Weather Automatic Station and published on the BOM's website where it was collected. The missing and invalid measurements account for approximately $0.01 \%$ of the whole database of global solar radiation; those were replaced with the values of preceding or subsequent days by interpolation. During the calculations process, any year found with more than ten days in any month observations not available was excluded. "Table 1" provides geographical information for Armidale town and the periods of the relevant global solar radiation data. 
Table 1 Geographical and solar radiation database information of Armidale NSWAustralia Longitude $(\dagger \mathrm{\dagger})$ Latitude $(\dagger \mathrm{S})$ Elevation $(\mathrm{m}) \quad$ Daily Global Solar Radiation Data

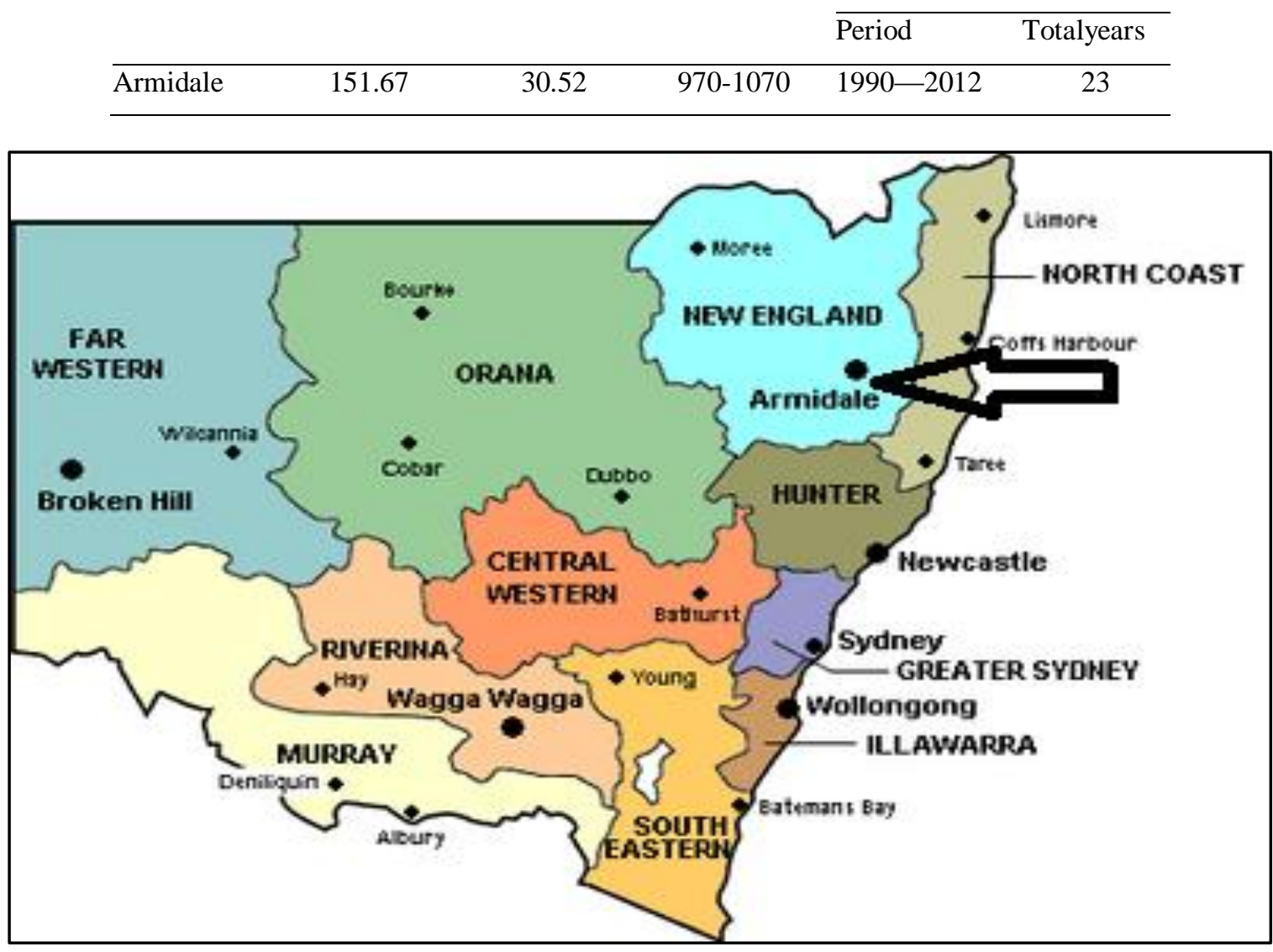

Figure1 Armidale NSWAustralia location

\section{METHODOLOGY}

Finkelstein-Schafer (FS) statistics [11] is a nonparametric statistical method, known as common methodology for generating typical weather data [1, 2, 3, 4, 5, 8, 9, 10 \&12]. In this study, FS methodology is used for generating the typical solar radiation year. According to FS statistics [11], if a number, n, of observations of a variable $\mathrm{X}$ are available and have been sorted into an increasing order $\mathrm{X} 1, \mathrm{X} 2, \ldots$., Xn, the cumulative frequency distribution function (CDF) of this variable is given by a function $\operatorname{Sn}(\mathrm{X})$, which is defined in equation (1).

$$
S_{n}(X)=\left\{\begin{array}{ccc}
0 & \text { For } X<X_{1} \\
\frac{(K-0.5)}{n} & \text { For } X_{k}<X<X_{K+1}(1) \\
1 & \text { For } & X>X_{n}
\end{array}\right.
$$

where $\mathrm{k}$ is rank order number. The FS by which comparison between the long-term CDF of each month and the $\mathrm{CDF}$ for each individual year of the month was done is given in equation (2).

$$
F S=(1 / N) \sum_{i=1}^{n} \delta_{i}(2)
$$

where $\mathrm{i}$ is the absolute difference between the long-term CDF of the month and one-year CDF for the same month at $\mathrm{Xi}(\mathrm{i}=1,2, \mathrm{n}), \mathrm{n}$ being the number of daily readings of the month. di and $\mathrm{F}(\mathrm{Xi})$ are expressed with the following equations $(3 \& 4)$.

$$
\delta_{i}=\max \left[\left|F\left(X_{I}\right)-\frac{(i-1)}{n}\right|,\left|F\left(X_{i}\right)-\frac{i}{n}\right|\right](3)
$$




$$
F\left(X_{i}\right)=1-\exp \left(-X_{i} / \bar{X}\right)(4)
$$

where $\mathrm{Xi}$ is an order sample value in a set of $\mathrm{n}$ observations sorted in an increasing order and $\mathrm{X}$ is the sample average.

Finally, the representative year for each month of the data set was determined on the basis that the representative year is that of the smallest value of FS as in equation (5).

$$
\operatorname{TRY}=\operatorname{MIN}(F S)=\operatorname{MIN}\left(\delta_{i}\right)(5)
$$

\section{GENERATION OF TYPICAL SOLAR RADIATION YEAR}

Applying the above methodology for all the months in the database, the Test Reference Year for daily global solar radiation data was formed for Armidale.

The test reference years with minimum FS for monthly mean global solar radiation for Armidale are given in "Table 2". Which shows that, although the big picture that Armidale has a high potential of solar energy, still there are considerable differences of potentiality in through the months due to the fact that Armidale's Winter season (June, July and August) is relatively cloudy. "Table 2", the minimum and maximum values of monthly mean of the daily global solar radiation on a horizontal surface (ITRY) in Armidale, the minimum is $10.41 \mathrm{MJ} / \mathrm{m} 2$ day in June and the maximum is $25.88 \mathrm{MJ} / \mathrm{m} 2$ day in December.

Table2TestReferenceYearswithminimum (min)FSandmonthlymeanofthedailyglobalsolarradiation(ITRY) for Armidale NSWAustralia

\begin{tabular}{|c|c|c|}
\hline Month & Year & ITRY $\left(\mathrm{MJ} / \mathrm{m}^{2}\right.$ day $)$ \\
\hline January & 1993 & 25.33 \\
\hline February & 2007 & 25.18 \\
\hline March & 1993 & 19.68 \\
\hline April & 1993 & 15.98 \\
\hline May & 2000 & 12.4 \\
\hline June & 2006 & 10.41 \\
\hline July & 1991 & 11.44 \\
\hline August & 1999 & 14.62 \\
\hline September & 2012 & 19.11 \\
\hline October & 1991 & 22.00 \\
\hline November & 1991 & 23.59 \\
\hline December & 1994 & 25.88 \\
\hline
\end{tabular}

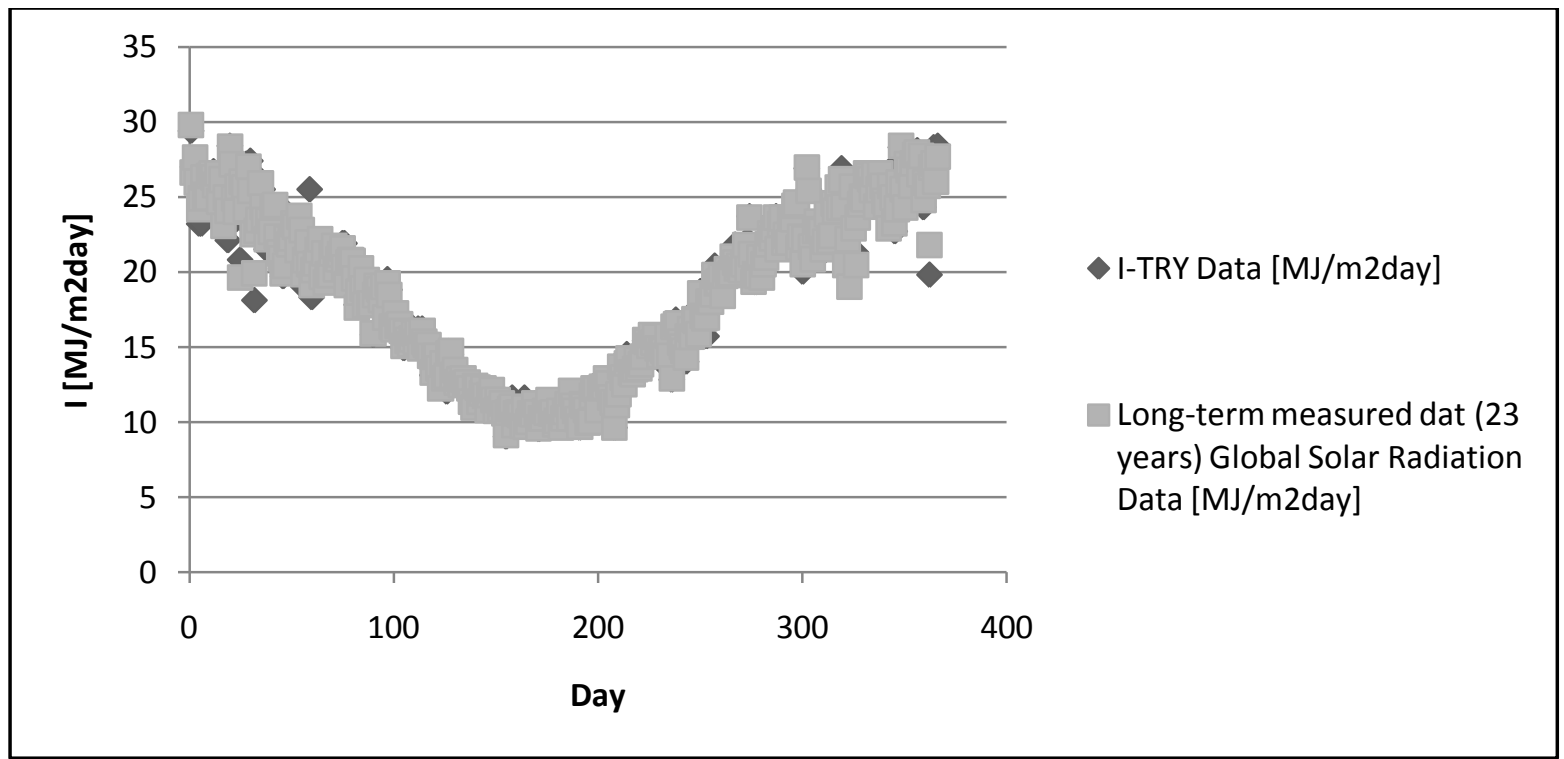

Figure2Variation ofdaily globalsolarradiationforArmidale NSW Australia 
Table3Dailyglobalsolar radiationvaluesobtainedfromTestReferenceYear data for Armidale NSWAustralia

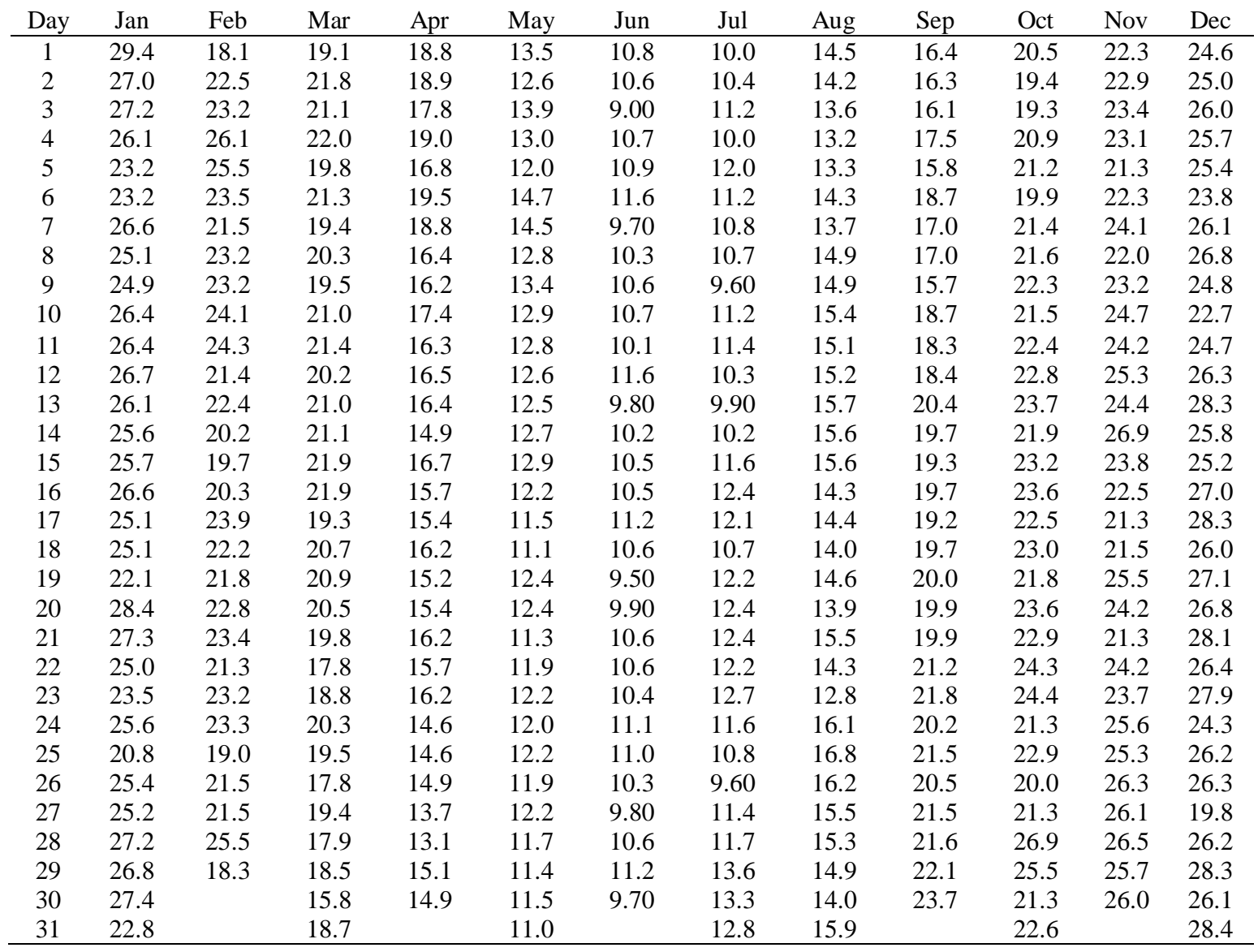

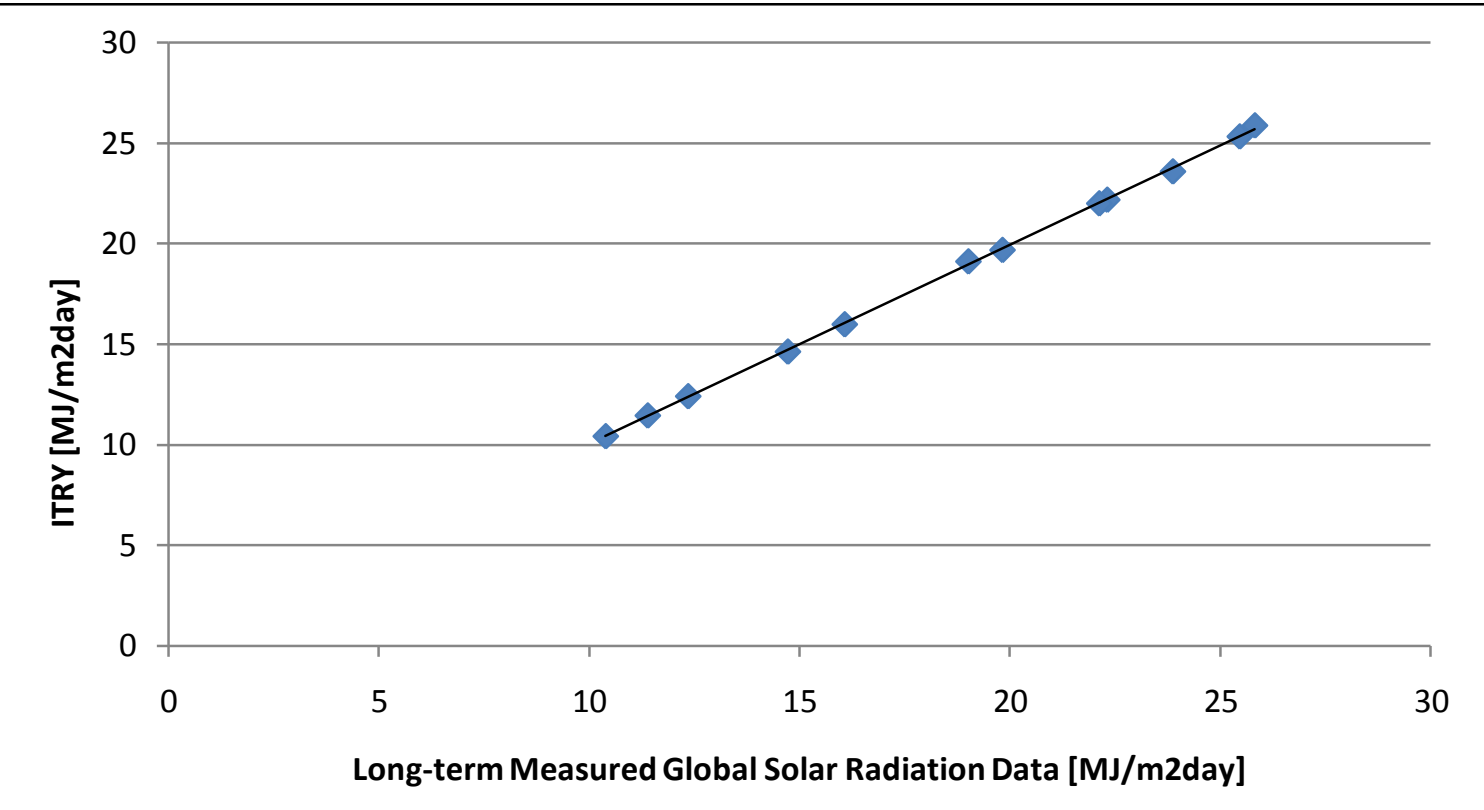

Figure 3 Comparison of monthly averages of the long-term measured global solar radiation data and TRY data forArmidale NSW Australia

"Fig. 2" shows the variation of the daily global solar radiation on a horizontal surface generated from test reference year and all the available long-term measured data for Armidale. Apparently, there is a significant, in the same time, random fluctuation throughout the year daily basis. 
"Fig. 3" depicts typical solar radiation (ITRY) generated data compared with the long-term measured data set. It shows the differences between ITRY data and the measured data for all the locations considered in this study on a monthly basis for daily global solar radiation. As shown in "Fig. 3", there is an agreement on a monthly basis. It is seen that the ITRY data is quite favourable on a monthly basis.

\section{CONCLUSION}

Typical solar radiation data is very important for calculations concerning many solar energy generation systems and for building energy calculation modelling and analysis. In this study, test reference years for daily global solar radiation for Armidale town NSW, Australia are generated using 23 years of the meteorologically measured data. The daily global solar radiation on a horizontal surface for the region is presented throughout the year in a tabular form. Results show that both long-term measured and the typical data are very random throughout the year on daily basis. It is found that there is a clear agreement between the long-term data and typical data on a monthly basis. As well, the results show that Armidale has a high potential of solar energy through most of the year except for the winter months, which is still potential but not high. The generated test reference year would be a useful reference for energy systems designers for any type of building applications.

\section{REFERENCES}

[1] A. Argiriou, S. Lykoudis, S. Kontoyiannidis, C.A. Balaras, D. Asimakopoulos, M. Petrakis, and P.Kassomenos. Comparison of methodologies for TMY generation using 20 years data forAthens, Greece. Solar Energy 66(1), 1999, 33-45.

[2] W. Marion and K. Urban. User's Manual for TMY2s. National Renewable Energy Laboratory, Colorado, USA, 1995.

[3] H. Bulut. Generation of typical solar radiation data for Istanbul, Turkey. International Journal of Energy Research 27(9), 2003, 847-855.

[4] H. Bulut. Typical Solar Radiation Year for South-eastern Anatolia. Renewable Energy 29(9), 2004, 1477-1488.

[5] R.L. Fagbenle. Generation of a test reference year for Ibadan, Nigeria. Energy Conversion andManagement 30(1), 1995, 61-63.

[6] J.C. Lam, S.C.M. Hui, and A.L.S. Chan. A statistical approach to the development of a typicalmeteorological year for Hong Kong. Architectural Science Review 39(4), 1996, 201-209.

[7] A. Miguel, and J. Bilbao. Test reference year generation from meteorological and simulatedsolar radiation data. Solar Energy 78(6), 2005, 695-703.

[8] M. Petrakis, H.D. Kambezidis, S. Lykoudis, A.D. Adamopoulos, P. Kassomenos, I.M. Michaelides, S.A. Kalogirou, G. Roditis, I. Chrysis, and A. Hadjigianni. Generation of a typical meteorological year for Nicosia, Cyprus. Renewable Energy: 13(3), 1998, 381-388.

[9] S.A.M. Said and H.M. Kadry. Generation of representative weather-year data for SaudiArabia. Applied Energy 48(2), 1994, 131-136.

[10] M.A.M. Shaltout and M.T.Y. Tadros. Typical solar radiation year for Egypt. Renewable Energy 4(4), 1994, 387-393.

[11] J.M. Finkelstein and R.E. Schafer. Improved goodness of fit tests. Biometrika 58(3), 1971, 641-645.

[12] G. Kalogirou, I. Roditis,, II. Chrysis, and A. Hadjigianni. Generation of a typical meteorological year for Nicosia, Cyprus. Renewable Energy: 13(3), 1998, 381-388. 